\title{
Public knowledge of risk factors and warning signs for cardiovascular disease among young and middle-aged adults in rural Tanzania
}

Alfa J. Muhihi ${ }^{1,2,3^{*}}$ D, Amani Anaeli ${ }^{4}$, Rose N. M. Mpembeni ${ }^{5}$, Bruno F. Sunguya ${ }^{1}$, Germana Leyna ${ }^{5}$, Deodatus Kakoko ${ }^{6}$, Anna Tengia Kessy ${ }^{1}$, Mary Mwanyika Sando², Marina Njelekela ${ }^{7,8}$ and David P. Urassa ${ }^{1}$

\begin{abstract}
Background: Improving cardiovascular health requires public knowledge and reduction of modifiable cardiovascular disease (CVD) risk factors. This study assessed knowledge of risk factors and warning signs for CVDs among young and middle-aged adults in Morogoro, Tanzania.

Methods: We conducted a community-based survey as part of cluster randomized controlled study of community health workers (CHWs) intervention for reduction of blood pressure among young and middle-aged adults in rural Morogoro. Information on socio-demographic characteristics, knowledge of risk factors and warning signs for CVDs was collected using an interviewer administered questionaire. Knowledge was assessed using open-ended questions followed by closed-ended questions. Descriptive statistics were used to describe knowledge of risk factors and warning signs. Logistic regression analysis was used to investigate factors associated with adequate knowledge of risk factors and warning signs for CVDs.

Results: Two-thirds (65.7\%) of the participants had heard about CVDs. The main sources of information were mainly relatives/ neighbors (64.8\%) and radio (53.0\%). Only $28.3 \%$ of the participants reported health care providers as source of information about CVDs. More than half of the participants (52.4\%) did not mention even one risk factor spontaneously while $55.2 \%$ were unable to mention any warning sign. When asked to select from a list, $6.9 \%$ were unable to correctly identify any risk factor whereas $11.8 \%$ could not correctly identify even a single warning sign. Quarter of participants (25.4\%) had good knowledge score of risk factors, 17.5\% had good knowledge score of warning signs and $16.3 \%$ had overall good knowledge of both risk factors and warning signs. Residing in Ulanga, having higher education level, having ever checked blood pressure and being overweight/obese predicted adequacy of knowledge score for both risk factors and warning signs.

(Continued on next page)
\end{abstract}

\footnotetext{
* Correspondence: selukundo@gmail.com

${ }^{1}$ Department of Community Health, Muhimbili University of Health and

Allied Sciences, United Nations Road, P. O. Box 65001, Upanga, Dar es

Salaam, Tanzania

${ }^{2}$ Africa Academy for Public Health, Plot \# 802, Mwai Kibaki Road, Mikocheni,

Dar es Salaam, Tanzania

Full list of author information is available at the end of the article
}

(c) The Author(s). 2020 Open Access This article is licensed under a Creative Commons Attribution 4.0 International License, which permits use, sharing, adaptation, distribution and reproduction in any medium or format, as long as you give appropriate credit to the original author(s) and the source, provide a link to the Creative Commons licence, and indicate if changes were made. The images or other third party material in this article are included in the article's Creative Commons licence, unless indicated otherwise in a credit line to the material. If material is not included in the article's Creative Commons licence and your intended use is not permitted by statutory regulation or exceeds the permitted use, you will need to obtain permission directly from the copyright holder. To view a copy of this licence, visit http://creativecommons.org/licenses/by/4.0/. The Creative Commons Public Domain Dedication waiver (http://creativecommons.org/publicdomain/zero/1.0/) applies to the data made available in this article, unless otherwise stated in a credit line to the data. 
(Continued from previous page)

Conclusion: Knowledge of risk factors and warning signs in this rural population of young and middle-aged adults was generally low. Health care providers were less likely to provide health education regarding risk factors and warning signs for CVDs. Health promotion interventions to increase population knowledge of risk factors and warning signs should be implemented for successful reduction of CVDs in Tanzania.

Keywords: Knowledge, Cardiovascular diseases, Risk factors, Warning signs, Tanzania

\section{Background}

Cardiovascular Diseases (CVDs), a group of disorders that affect the heart and/or blood vessels are the leading causes of deaths and disability-adjusted life-years (DALYs) globally [1, 2]. In 2017, CVDs accounted for an estimated 17.8 million deaths, with more than $80 \%$ occurring in lowand middle-income countries (LMICs) [2]. It is projected that by the year 2030, CVDs will cause more than 23.6 million deaths [3] with stroke and coronary heart diseases being the main contributors. The rising burden of CVDs in LMICs is fueled by higher prevalence of risk factors such as smoking, physical inactivity, unhealthy dietary habits, overweight and obesity [4]. Population level reduction in risk factors such as blood pressure, total cholesterol, smoking and physical inactivity contributed to significant decline in CVD-related morbidity and mortality in high income countries [5-7].

A crucial step towards reduction in CVDs and improvement in cardiovascular health requires public knowledge of risk factors. Studies have shown that knowledge of CVDs and their risk factors can lead to success in their prevention and control [8] by influencing individual attitude and practices towards healthy lifestyle [9], improved compliance with treatment and decreased risk of disease complications [10]. The world health organization (WHO) promotes knowledge of behavioral CVD risk factors [11]. Already, some studies have assessed knowledge of CVD and risk factors in Africa among the general community [12-17], while a few others have done so in specific population groups [18-24].

Knowledge of risk factors for CVDs in sub-Saharan Africa (SSA) is generally poor. Findings from a systematic review of studies conducted in SSA indicated low levels of knowledge coupled with unfavorable perception towards CVD risk [25]. Another report from Uganda found that up to three-quarter of the surveyed population were unable to identify even a single risk factor or clinical symptom for CVD [16]. Understanding of the community about CVDs has significant positive implications as it helps development of targeted health education and promotion programs for prevention and control of CVDs [26].

Despite the rising prevalence CVDs and their related risk factors in Tanzania [27, 28], there are no published studies to date that have comprehensively assessed knowledge of CVDs and their risk factors in the Tanzanian general population. Understanding knowledge, perception and practices is crucial to inform the design and implementation of context appropriate intervention for prevention of the rising burden of CVDs in Tanzania. This study assessed knowledge of risk factors and warning signs for CVD among young and middle-aged adults in rural Tanzanian and further explored factors associated with knowledge.

\section{Methods \\ Study design and setting}

The study design and data collection methods have already been described elsewhere [29]. A baseline survey was conducted between 15th July and 30th August, 2019 as part of a cluster randomized controlled trial of Community Health Workers (CHWs) interventions for reduction of blood pressure among adults aged 25-64 years in Kilombero and Ulanga districts. The study area is approximately $450 \mathrm{~km}$ by road South-West of the Tanzania's commercial capital of Dar es salaam. Kilombero and Ulanga districts cover a total surface area of $28,669 \mathrm{~km}^{2}$. Based on the 2012 national census and the average annual population increase for Morogoro region [30], Kilombero and Ulanga districts were projected to have a total population of 659,810 by end of 2019 . The predominant tribes in Kilombero and Ulanga districts are Wapogolo and Wandamba with the main economic activities being maize and rice farming as well as fishing activities on the Kilombero river.

The baseline survey was conducted in 12 randomly selected villages (6 from Kilombero district and another 6 from Ulanga district) in Morogoro region. Study villages were selected from a list of 38 villages which had active CHWs at the time of randomization. For the CHWs intervention study, three villages from each district were assigned to intervention arm and the remaining three to control arm. Conditional randomization was done to ensure equal number of villages are assigned to intervention and control in each district. Based on the local government registries, the number of households per village ranged from 1587 to 5929 and a total of 262 households were randomly selected from each of the 12 study villages. 


\section{Study participants and eligibility criteria}

The study population included young and middle-aged adults 25-64 years, who resided in the selected villages and provided a written informed consent to participate. A resident was defined based on the Health and Demographic Surveillance System (HDSS) definition as an individual who has stayed in the selected household for at least 4 months continuously regardless of whether s/he had slept in that household a night before the interview [31]. A household was defined as group of people who served food from the same pot.

\section{Sample size estimation and sampling procedures}

The sample size was estimated according to the methods proposed in the WHO stepwise approach to chronic disease risk factors surveillance (STEPS) [32]. The sample size was calculated for $95 \% \mathrm{CI}(\mathrm{z}=1.96)$ on the basis of a $5 \%$ margin of error and an estimated prior population prevalence of hypertension of $25.9 \%$ from the national wide representative STEPS survey in Tanzania [33], a presumed design effect of 1.2 and an anticipated nonresponse rate of $10 \%$. Participants were adults aged 25-64 years and categorized into four age-sex groups, resulting into 8 strata. The resulting minimum sample size for the study was 3145 .

We used multi-stage cluster sampling technique with villages as clusters. The villages were stratified by district, to obtain equal number of villages in both districts. Furthermore, a random sample of 262 households was drawn for all villages and at each selected household, one eligible respondent was selected for interview. The next birthday rule was used to select one eligible respondent from a household where the research assistants first noted the months of birth of all eligible individuals in a household in ascending order (January - December). The first person on the list was then selected for interview, and if the selected person was not available after two attempts, then the next person on the list was interviewed. Non-response was considered if an eligible participant refused/did not consent to participate or the selected household had only one eligible responded who could not be found after two follow up attempts.

\section{Data collection procedures}

Face-to-face interviews were conducted by a team of trained research assistants with experience in conducting health and demographic surveys. A modified WHO STEPs questionnaire was used for data collection (supplementary file). Information collected during the interviews included socio-demographic and economic characteristics, knowledge of risk factors and warning signs for cardiovascular diseases, medical history, behavioral characteristics and physical measurements.

\section{Socio-demographic and economic characteristics}

Socio-demographic information included age, gender, marital status, education level, and occupation. Age was collected as a continuous variable and categorized into 25-34, 35-44, 45-54, and 55-64 years. Education level was measured by asking the highest education level attained as none, primary education, secondary education, college/university. Marital status at the time of data collection was grouped into three groups as never married, married or living together and divorced /separated /widowed. Occupation was assessed and categorized as farmer, housewife, employed (public/private), petty business and others. Economic status of the participants was assessed through ownership of household items such as radio, television, telephone, sofa, refrigerator, bicycle, car, and having working electricity; house ownership, construction materials (floor, walls and roofing materials); source of fuel for cooking and lighting; source of water supply for home use and drinking; and household sanitation facility [34]. All this information was used to generate household wealth index following descriptions in the Demographic Health Survey (DHS) toolkit [35].

\section{Assessment of CVD knowledge}

To assess general knowledge, participants were asked if they had ever heard or read about CVDs and their sources of information. Knowledge of risk factors and warning signs was then assessed using open-ended questions (participants were asked to mention risk factors and warning signs spontaneously) followed by closedended questions (participants were asked to identify risk factors and warning signs from a list of "yes/no" questions). The questionnaire comprised of 10 -items about knowledge of risk factors and 9-items on knowledge of warning signs. Knowledge scores were assigned as 1 (one) for each correct response and 0 (zero) for wrong response. Knowledge scores were calculated based on closed-ended questions.

The score points were then summed across to obtain a total score for knowledge of risk factors and warning signs separately. Total scores for knowledge of risk factors were categorized as; good (7-10 points), moderate (4-6 points), poor knowledge (1-3 points) and not knowledgeable at all ( 0 point). Total scores for knowledge of warning signs were categorized as; good (7-9 points), moderate (4-6 points) and poor knowledge (1-3 points) and not knowledgeable at all (0 point). Internal consistency and reliability of each set of items for assessment of knowledge of risk factors and warning signs was evaluated using Cronbach's alpha test. The reliability coefficients were 0.826 for the scale of knowledge of risk factors and 0.782 for the scale of knowledge of warning signs. The two scales were reliable as Robinson and colleagues assert, an alpha coefficient above 0.80 is 
"exemplary", and that in the range between 0.70 and 0.79 is "extensive" [36].

Total knowledge of CVDs was assessed by combining the total knowledge scores for risk factors and warning signs. The maximum possible total knowledge score was 19 points. Participants who obtained total knowledge score of $\geq 14$ points were classified as having "good knowledge", those with total knowledge score between 8 and 13 points were classified as having "moderate knowledge", those with total knowledge score between 1 and 7 points were classified as having "poor knowledge", and those who did not get any score as "not knowledgeable".

\section{Medical history and behavioral risk factors}

Participants were asked if they had ever been diagnosed with hypertension or diabetes mellitus. Lifestyle related CVD risk factors including smoking, alcohol drinking, and dietary habits were assessed using a modified WHO STEPs questionnaire (supplementary file) which has been previously used in Tanzania [33]. Questions on smoking probed current and past smoking while questions for alcohol probed current and past drinking. Dietary assessment included frequency of consumption of fruits and vegetables (in days per week), and frequency of use of raw table salt (as never, sometimes or always).

\section{Perceptions about CVD and practices towards CVD prevention}

The study questionnaire also contained a section with set of questions that assessed participant's self-perceived risk for cardiovascular disease, perception about current body weight, general practices, dietary practices, and behavioral practices in the past 1 year that relate to better cardiovascular health and prevention of CVDs.

\section{Physical measurements}

Blood pressure was measured using a digital blood pressure machine (OMRON HEM-712C, Omron Healthcare, Inc). Research assistants were trained to measured blood pressure on the left arm with participant in a seated position. The first reading was taken after at least $5 \mathrm{~min}$ of resting. The second and third readings were taken half-way and at the end of interview respectively. Participants who had elevated blood pressure had blood pressure measurements repeated on the following day to confirm their elevated blood pressure before being given referral letter to nearby health facility for proper diagnosis and management per standing national guidelines. For these individuals, we used their repeat blood pressure measurements for analysis. An average of three blood pressure measurements was used during analysis. Hypertension was defined as average systolic blood pressure (SBP) $\geq 140$ $\mathrm{mmHg}$ and/or diastolic blood pressure (DBP) $\geq 90 \mathrm{mmHg}$ and/or currently taking blood pressure lowering medications in accordance with the Seventh Report of the Joint
National Committee on Prevention, Detection, Evaluation and Treatment of High Blood Pressure [37]. Anthropometric measurements included weight and height. Body weight was measured to the nearest $0.1 \mathrm{~kg}$ using a SECA 803 digital scale placed on flat ground with participant wearing light clothing and with no shoes. Height was measured to the nearest $0.1 \mathrm{~cm}$ with participant in a standing position with heels perpendicular to the portable stadiometer. Body mass index (BMI) was calculated using measured weight and height $\left(\mathrm{kg} / \mathrm{m}^{2}\right)$.

\section{Data analysis}

Data were entered and analysed using IBM-Statistical Package for Social Sciences (SPSS Inc., Chicago, IL, USA) version 20 software for Windows. Descriptive statistics were used to summarize continuous variables as means with standard deviations and categorical variables as frequencies with proportions. Comparisons between groups were done using Chi-square test and independent samples t-test (or ANOVA) for categorical and continuous variables respectively.

To perform logistic regression, knowledge of CVD risk factors and warning signs was first dichotomized by combining good knowledge and moderate knowledge as having "adequate knowledge" and those with poor and not knowledgeable as having "inadequate knowledge". Bivariate logistic regression was then performed to determine the relationship of each independent variable with CVD knowledge score. Predictor variables were categorized as: sex, age, wealth status, marital status, education level, place of residence, occupation, current smoker, current alcohol drinker, use of raw table salt, fruits consumption per week, vegetable consumption and body mass index.

All variables with $p \leq 0.2$ in the bivariate analysis were included in the multiple logistic regression analysis to determine factors that are independently associated with overall adequate CVD knowledge. Before fitting multiple logistic regression model, we first checked for correlation and strength of correlation between variables in the regression model to avoid problem with multicollinearity. We used variance inflation factor (VIF) with a cut-off value of $\leq 5$ to rule out multicollinearity. Overall fitness of the model was assessed using the Pearson Chisquare test and Hosmer-Lemeshow goodness-of-fit test. Adjusted odds ratio (AOR) with their corresponding 95\% confidence intervals (95\% CI) are presented as measures of association. Statistical significance was accepted based on two-sided $p$-value $\leq 0.05$.

\section{Results}

General characteristics of study participants

A total of 3000 participants had complete data for analysis, giving a response rate of $95.4 \%$. General characteristics of the study population are described in Table 1 . 
Table 1 Characteristics of the study participants

\begin{tabular}{|c|c|}
\hline Variable & n (\%) or median (IQR) \\
\hline Age (Years) [Median (IQR)] & $39(31.0-48.0)$ \\
\hline \multicolumn{2}{|l|}{ Age group (Years) } \\
\hline $25-34$ & $1072(35.7)$ \\
\hline $35-44$ & $888(29.6)$ \\
\hline $45-54$ & $628(20.9)$ \\
\hline $55-64$ & $412(13.7)$ \\
\hline \multicolumn{2}{|l|}{ Sex } \\
\hline Males & $778(25.9)$ \\
\hline Females & $2222(74.1)$ \\
\hline \multicolumn{2}{|l|}{ District of residence } \\
\hline Kilombero & $1500(50.0)$ \\
\hline Ulanga & $1500(50.0)$ \\
\hline \multicolumn{2}{|l|}{ Marital status } \\
\hline Never married & $383(12.8)$ \\
\hline Married & $2144(71.5)$ \\
\hline Separated/Divorced/Widowed & $473(15.8)$ \\
\hline \multicolumn{2}{|l|}{ Education level } \\
\hline No formal education & $297(9.9)$ \\
\hline Primary education & $2411(80.4)$ \\
\hline Secondary education & $255(8.5)$ \\
\hline College/university education & $37(1.2)$ \\
\hline \multicolumn{2}{|l|}{ Occupation } \\
\hline Farmer & $2775(92.5)$ \\
\hline House wife & $79(2.6)$ \\
\hline Employed & $27(0.9)$ \\
\hline Petty business & $80(2.7)$ \\
\hline Other $^{\mathrm{a}}$ & $39(1.3)$ \\
\hline \multicolumn{2}{|l|}{ Current smoking status } \\
\hline Yes & $176(5.9)$ \\
\hline No & $2824(94.1)$ \\
\hline \multicolumn{2}{|l|}{ Current alcohol drinking status } \\
\hline Yes & $591(19.7)$ \\
\hline No & $2409(80.3)$ \\
\hline \multicolumn{2}{|l|}{ History of Diabetes Mellitus } \\
\hline Yes & $29(1.0)$ \\
\hline No & $2971(99.0)$ \\
\hline \multicolumn{2}{|l|}{ Hypertensive } \\
\hline Yes & $880(29.3)$ \\
\hline No & $2120(70.7)$ \\
\hline \multicolumn{2}{|l|}{ Body Mass Index [BMI $\left.\left(\mathrm{kg} / \mathrm{m}^{2}\right)\right]$} \\
\hline Normal & $1563(52.1)$ \\
\hline Overweight & $855(28.5)$ \\
\hline Obese & $489(16.3)$ \\
\hline Underweight & $93(3.1)$ \\
\hline
\end{tabular}

ather occupations included: retired (0.3\%), student $(0.1 \%)$, no job (0.5\%) and declined to respond $(0.4 \%)$
The median age [interquartile range (IQR)] of the participants was 39 [31-48] years. Majority of the participants were women $(74.1 \%)$, were married $(71.5 \%)$, had primary education $(80.4 \%)$ and were predominantly farmers (92.5\%). With regard to behavioral and physiological characteristics, 5.9 and $19.7 \%$ of the participants were current smokers and alcohol drinkers respectively. Most participants $(85.2 \%)$ used table salt, with $6.8 \%$ reporting to do so always. Less than two-thirds (63.9\%) reported to consume vegetables 5-7 days per week while only $7.9 \%$ consumed fruits 5-7 days per week. More than quarter of participants (29.3\%) were hypertensive, $28.5 \%$ were overweight $(28.5 \%)$ and $16.3 \%$ were obese.

\section{General knowledge about CVDs}

As presented in Table 2, about two-thirds (65.7\%) of the participants had heard or read about CVDs. The main sources of information were relatives/neighbors (64.8\%) and radio $(53.0 \%)$. Only $28.3 \%$ of the participants reported health care providers as source of information about CVDs. There were significant gender differences in the sources of information about CVDs with radio and television being most common sources of information among men (all $p<0.001$ ). On the contrary, higher proportion of women reported to have heard about CVDs from health care providers and relatives/neighbors (all $p<0.001$ ).

\section{Knowledge of risk factors and warning signs}

Results on participant's knowledge of risk factors are summarized in Table 3. Most participants were not knowledgeable about risk factors when asked openended questions. Stress (35.8\%) and cholesterol (18.5\%) were the frequently mentioned risk factors. On asking closed-ended questions most participants identified stress (85.4\%), obesity (67.7\%), cholesterol (64.3\%) and physical inactivity (63.3\%). The least identified risk factors were family history of stroke (18.4\%) and alcohol drinking (25.5\%). Although half of the participants (51.4\%) were able to identify five or more risk factors, 207 (6.9\%) were unable to identify any risk factor.

Table 4 summarizes results of knowledge of warning signs for CVDs. When asked open-ended questions, again most participants had poor knowledge of warning signs. Only 24.5 and $18.4 \%$ of the participants mentioned shortness of breath and headache respectively as warning signs. On closed-ended questions, warning signs correctly identified by most participants were shortness of breath (74.3\%), loss of consciousness (63.7\%), headache $(60.8 \%)$ and dizziness (60.2\%). Jaw or neck pain (10.6\%) and vomiting $(11.0 \%)$ were the least identified warning signs.

Participants' knowledge scores for risk factors, warning signs and both combined are presented in Table 5. At 
Table 2 Awareness and source of information about CVDs

\begin{tabular}{|c|c|c|c|c|}
\hline $\begin{array}{l}\text { Knowledge about } \\
\text { CVDs }\end{array}$ & $\begin{array}{l}\text { All }(N=3000) \\
\text { Yes, } n(\%)\end{array}$ & $\begin{array}{l}\text { Men }(N=778) \\
\text { Yes, } n(\%)\end{array}$ & $\begin{array}{l}\text { Women }(N=2222) \\
\text { Yes, n (\%) }\end{array}$ & $\begin{array}{l}P- \\
\text { value }\end{array}$ \\
\hline \multicolumn{5}{|c|}{ Ever heard or read about CVDs } \\
\hline Yes & $1971(65.7)$ & $526(67.6)$ & $1445(65.7)$ & 0.192 \\
\hline No & $1029(34.3)$ & $252(32.4)$ & $777(35.0)$ & \\
\hline \multicolumn{5}{|l|}{ Source of information } \\
\hline Radio & $1045(53.0)$ & $327(62.2)$ & $718(53.0)$ & $<0.001$ \\
\hline Television & $164(8.3)$ & $64(12.2)$ & $100(6.9)$ & $<0.001$ \\
\hline Newspapers & $22(1.1)$ & $13(2.5)$ & $9(0.6)$ & 0.001 \\
\hline Health care providers & $558(28.3)$ & $100(19.0)$ & $458(31.7)$ & $<0.001$ \\
\hline Relative/neighbor & $1278(64.8)$ & $284(54.0)$ & $994(68.8)$ & $<0.001$ \\
\hline Internet/social media & $20(1.0)$ & $9(1.7)$ & $11(0.8)$ & 0.063 \\
\hline Other sources & $13(0.7)$ & $3(0.6)$ & $10(0.7)$ & 0.768 \\
\hline
\end{tabular}

least one in four participants had good knowledge while $35.7 \%$ had either poor or no knowledge at all about risk factors. As for warning signs, only $17.5 \%$ of the participants had good knowledge of warning signs whereas $40.1 \%$ had either poor or no knowledge of warning signs. Overall, only $16.3 \%$ of the participants had good knowledge of both risk factors and warning signs while $42.8 \%$ had moderate knowledge. The remaining $40.9 \%$ had poor or were not knowledgeable at all about risk factors and warning signs for CVDs.

\section{Predictors of adequate knowledge of risk factors and warning signs}

Table 6 summarizes predictors of adequate knowledge of risk factors and warning signs for CVDs in the study population. Sociodemographic characteristics associated with adequate knowledge were older age, male sex, being married, higher education level and employment status (all $p<0.05$ ). Middle aged participants had significantly higher knowledge of warning signs compared to their counterpart younger participants. Men had good knowledge of risk factors than women, though no significant differences were observed for knowledge of warning signs. Participants from Ulanga district had significantly higher knowledge compare to Kilombero district $(p<$ 0.001). Participants who reported to smoke had adequate knowledge of risk factors and warning signs than those who did not $(p=0.014)$. As for medical history, participants with history of diabetes mellitus, ever checked blood pressure and those who were hypertensive had higher knowledge (all $p<0.05$ ).

Self-perceived risk and practices towards CVD prevention Nearly half $(45.3 \%)$ of the participants perceived themselves to be at risk of cardiovascular disease. Although it was not statistically significant, women perceived themselves to be at risk of CVD more than men $(75.7 \%$ vs
$24.3 \%, p=0.069$ ). As for body weight, $30.7 \%$ perceived themselves to be overweight or obese. We found significant difference between actual body weight and perception about body weight where only about half (52.6\%) of overweight and obese participants perceived their weight as overweight and obese $(p<0.001)$. Nearly one-third $(31.9 \%)$ of the participants perceived that their body weight had increased in the past 1 year. With regard to practices, $5.7 \%$ of smokers had attempted to stop or decreased smoking while $21.7 \%$ had decreased drinking alcohol in the past 1 year. Other practices for prevention of CVD are shown in Table 7.

\section{Discussion}

To the best of our knowledge, the present study is the first to conduct comprehensive assessment of knowledge of risk factors and warning signs for CVDs and predictors of adequate knowledge scores among young and middle-aged adults in rural Tanzania.

\section{Source of information about CVDs}

In our study, at least two-thirds of the participants had heard about CVDs. The main sources of knowledge of risk factors and warning signs for CVDs were relatives/ neighbors, radio, other health care providers and doctors. Internet and social media were the least mentioned sources of information in this population mainly because of the rural nature of the study setting. It is also possible that people use internet and social media for other things rather than search for health information. We also observed sex differences in the sources of information with radio being the main source of information among men while relatives/neighbors were the main source among women. Other studies have also reported radio [22-24], relatives/neighbors [13, 38, 39] and health care providers $[35,40,41]$ as sources of information for CVDs. Our findings have indicated underutilization of 
Table 3 Knowledge of risk factors for CVDs

\begin{tabular}{ll}
\hline & Number (\%) \\
\hline Spontaneous mention of risk factors for CVDs (Open-ended \\
questions) \\
Old age & $82(2.7)$ \\
Obesity & $277(9.2)$ \\
Hypertension & $73(2.4)$ \\
Diabetes mellitus & $51(1.7)$ \\
Cholesterol & $556(18.5)$ \\
Smoking & $17(0.6)$ \\
Alcohol drinking & $34(1.1)$ \\
Physical inactivity & $241(8.0)$ \\
Family history of stroke & $7(0.2)$ \\
Stress & $1073(35.8)$ \\
Number of risk factors mentioned (out of 10$)$ & $1574(52.4)$ \\
None & $1415(47.2)$ \\
1-4 & $11(0.4)$ \\
5-9 & $1542(51.4)$ \\
Selecting risk factors for CVDs from a list (Close-ended questions) \\
Old age & $1061(35.4)$ \\
Obesity & $2031(67.7)$ \\
Hypertension & $1098(36.6)$ \\
Diabetes mellitus & $1141(38.0)$ \\
Cholesterol & $1928(64.3)$ \\
Smoking & $794(26.5)$ \\
Alcohol drinking & $765(25.5)$ \\
Physical inactivity & $1899(63.3)$ \\
Nomily history of stroke & $552(18.4)$ \\
\hline
\end{tabular}

health care providers for provision of CVD-related health education. Deliberate efforts must be made to effectively use radio and health care providers as channels for delivery of health education programs to increase population knowledge of risk factors and warning signs in rural settings of Tanzania. A study in Kuwait demonstrated that higher knowledge of smoking, obesity, unhealthy diet and physical inactivity as CVD risk factors were attributable to their high mass media campaign [42].

\section{Knowledge of risk factors for CVDs}

In our study, we found low level of knowledge of risk factors for CVDs among study participants with only quarter (25.4\%) had good knowledge. Knowledge was
Table 4 Knowledge about warning signs for CVD event

\begin{tabular}{ll}
\hline & Number (\%) \\
\hline $\begin{array}{l}\text { Spontaneous mention of warning signs for CVD (Open-ended } \\
\text { questions) }\end{array}$ & $553(18.4)$ \\
Severe headache & $99(3.3)$ \\
Chest pain & $736(24.5)$ \\
Shortness of breath & $122(4.1)$ \\
Sweating while at rest & $15(0.5)$ \\
Vomiting & $16(0.5)$ \\
Pain in the jaw or neck & $169(5.6)$ \\
Pain in the arms or shoulder & $289(9.6)$ \\
Loss of consciousness & $280(9.3)$ \\
Dizziness & $1657(55.2)$ \\
Number of warning signs mentioned (out of 9) & $1322(44.1)$ \\
None & $21(0.7)$ \\
$1-4$ & $1374(43.8)$ \\
5-9 & $1332(44.4)$ \\
Selecting warning signs for CVD from a list (Close-ended \\
questions) \\
Severe headache & $1824(60.8)$ \\
Chest pain & $1324(44.1)$ \\
Shortness of breath & $2230(74.3)$ \\
Sweating while at rest & $1265(42.2)$ \\
Vomiting & $330(11.0)$ \\
Pain in the jaw or neck & $318(10.6)$ \\
Pain in the arms or shoulder & $1299(43.3)$ \\
Loss of consciousness & $1607(60.2)$ \\
Dizziness & \\
Number of warning signs identified (out of 9) & \\
\hline
\end{tabular}

much poor when we used open-ended questions as more than half of the participants $(52.4 \%)$ could not mention even a single CVD risk factor. However, knowledge of risk factors improved when closed-ended questions were used and the proportion of participants who could not identify even a single CVD risk factor dropped to $6.9 \%$. This improved knowledge with use of closed-ended questions may be due to most participants remembering risk factors when listed or guessed correct responses. More than half (51.4\%) of the participants identified five or more risk factors. Similar to our findings, other community based studies have also reported low level of knowledge of risk factors for CVDs in the general population [13-15, 39]. On the contrary, high knowledge has been reported among studies that focused on special populations like health care providers [43, 44], secondary 
Table 5 Participant knowledge scores for risk factors and warning for CVD event

\begin{tabular}{lc}
\hline & Number (\%) \\
\hline Knowledge scores on risk factors for CVDs & $762(25.4)$ \\
Good knowledge & $1167(38.9)$ \\
Moderate knowledge & $862(28.7)$ \\
Poor knowledge & $209(7.0)$ \\
Not knowledgeable & $524(17.5)$ \\
Knowledge scores on warning signs for CVD event \\
Good knowledge & $1274(42.5)$ \\
Moderate knowledge & $848(28.3)$ \\
Poor knowledge & $354(11.8)$ \\
Not knowledgeable & $488(16.3)$ \\
Overall knowledge scores for risk factors and warning signs \\
Good knowledge & $1285(42.8)$ \\
Moderate knowledge & $1073(35.8)$ \\
Poor knowledge & $154(5.1)$ \\
\hline
\end{tabular}

school teachers [23] and among staff of tertiary institution [45], meaning that education level and occupation have implication on health-related knowledge. Most participants in our study cited stress, obesity, cholesterol and physical inactivity as risk factors for CVDs. The proportion of participants who identified stress as a risk factor is comparable to that reported in a study conducted among Nigerian army force [24], but is much higher compare to other community based studies [14, 39, 46].

With exception of physical inactivity which was pointed out by nearly two thirds of the participants, smoking and alcohol were identified by only quarter of the participants as important risk factors for CVDs. A meta-analysis of 14 studies has shown smoking to be associated with up to $60 \%$ increased risk of stroke [47], and the risk was much higher for current smokers compared to ex-smokers. The literature also indicates a 30\% increased risk for stroke among individual with second hand smoke exposure compared to those with no exposure at all [48]. Although the reported prevalence of current smoker in our study was low (5.9\%), the national prevalence has previously been reported as $14.1 \%$ [49]. Thus, primary prevention interventions and particularly health education should be provided in order to increase population knowledge about risks associated with smoking and other modifiable risky behaviors like alcohol drinking and unhealthy diets.

\section{Knowledge of warning signs for CVD event}

Only $17.5 \%$ of the participants had good knowledge of warning signs while more than half $(55.2 \%)$ were not able to mention even a single warning sign for CVD event. Participants' knowledge of warning signs was lower than knowledge for risk factors. Poor knowledge of warning signs for CVD event found in this study is similar to what has previously been reported in East Africa. A study in Uganda found that $57 \%$ of the participants did not know stroke warning signs or symptoms [15], whereas a study in Kenya found poor knowledge of warning signs for coronary heart disease among people living with HIV [22].

Shortness of breath was the most commonly identified warning sign for CVD event in our study. Less than half (44.1\%) of participants identified chest pain as a warning sign for CVD event. These findings contrast results of the study that reported chest pain as the most commonly identified symptom [26]. Individuals with good knowledge of warning signs for CVD event are more likely to seek medical treatment early and consequently have better disease outcomes [50]. Additionally, people with good knowledge of both risk factors and warning signs tend to perceive themselves to be at higher risk for the disease and are more likely to adopt healthier lifestyle behaviors [51]. Thus, improving population knowledge of risk factors and warning signs for CVDs are likely to help adoption of healthier lifestyles for primary prevention, improve early medical care seeking behavior and consequently better prognosis among Tanzanians.

\section{Factors associated with CVD knowledge}

In our study, socio-demographic and economic characteristics were associated with knowledge of risk factors and warning signs for CVDs. Knowledge of both risk factors and warning signs was higher among men compared to women. Our findings of higher CVD knowledge among men differs from other studies which reported higher CVD knowledge among females [42, 52]. Nonetheless, several other studies have reported insignificant gender differences in CVD knowledge [15, 53-55]. Higher CVD knowledge among women has been attributed to less working time among women which gives them more leisure time to watch and listen to mass media such as radio, television and newspaper [42]. In contrary, our study had found men to be listening, watching and reading from mass media than women which may explain higher CVD knowledge among men. More men than women reported radio, television and newspapers to be their main sources of information about CVDs.

The current study showed that participants aged 4554 years were more knowledgeable about risk factors and warning signs compared to other age groups. These findings are suggestive that middle aged adults are more likely to seek health-related information than young individuals. Influence of age on CVD knowledge has also been reported by other studies conducted in SSA [39, 
Table 6 Multiple logistic regression models for predictors of adequate knowledge of risk factors and warning signs for CVDs among young and middle-aged adults in rural Morogoro, Tanzania $(N=3000)$

\begin{tabular}{|c|c|c|c|c|}
\hline \multirow[t]{2}{*}{ Variable } & \multicolumn{2}{|c|}{ Knowledge of risk factors } & \multicolumn{2}{|c|}{ Knowledge of warning signs } \\
\hline & AOR $(95 \% \mathrm{Cl})$ & $p$-value & AOR $(95 \% \mathrm{Cl})$ & $p$-value \\
\hline \multicolumn{5}{|l|}{ Age (years) } \\
\hline $25-34$ & Reference & & Reference & \\
\hline $35-44$ & $1.17(0.96-1.42)$ & & $1.22(1.01-1.49)$ & \\
\hline $45-54$ & $1.07(0.85-1.33)$ & 0.087 & $1.45(1.16-1.80)$ & 0.003 \\
\hline $55-64$ & $0.85(0.66-1.09)$ & & $0.98(0.76-1.26)$ & \\
\hline \multicolumn{5}{|l|}{ Gender } \\
\hline Male & Reference & & Reference & \\
\hline Female & $0.69(0.57-0.84)$ & $<0.001$ & $0.92(0.77-1.12)$ & 0.421 \\
\hline \multicolumn{5}{|l|}{ Marital status } \\
\hline Never married & Reference & & Reference & \\
\hline Married & $1.19(0.94-1.50)$ & 0.079 & $1.16(0.92-1.46)$ & 0.145 \\
\hline Separated/Divorced/Widowed & $0.96(0.72-1.29)$ & & $0.96(0.72-1.29)$ & \\
\hline \multicolumn{5}{|l|}{ Education level } \\
\hline No formal education & Reference & & Reference & \\
\hline Primary education & $1.45(1.23-1.87)$ & & $1.74(1.35-2.24)$ & \\
\hline Secondary education & $2.10(1.42-3.10)$ & 0.002 & $2.32(1.59-3.39)$ & $<0.001$ \\
\hline College/University & $2.22(0.92-5.39)$ & & $2.67(1.13-6.30)$ & \\
\hline \multicolumn{5}{|l|}{ District of residence } \\
\hline Kilombero & Reference & & Reference & \\
\hline Ulanga & $1.28(1.10-1.50)$ & 0.002 & $1.17(1.00-1.37)$ & 0.045 \\
\hline \multicolumn{5}{|l|}{ Occupation } \\
\hline Farmer & Reference & & Reference & \\
\hline House wife & $1.23(0.75-2.01)$ & & $1.04(0.64-1.67)$ & \\
\hline Employed & $0.92(0.34-2.45)$ & 0.519 & $1.03(0.40-2.65)$ & 0.170 \\
\hline Business & $1.51(0.89-2.58)$ & & $2.00(1.16-3.45)$ & \\
\hline Other & $0.85(0.42-1.69)$ & & $0.88(0.44-1.75)$ & \\
\hline \multicolumn{5}{|l|}{ Ever checked BP } \\
\hline Yes & Reference & & Reference & \\
\hline No & $0.55(0.47-0.66)$ & $<0.001$ & $0.51(0.43-0.60)$ & $<0.001$ \\
\hline \multicolumn{5}{|l|}{ Ever checked DM } \\
\hline Yes & Reference & & Reference & \\
\hline No & $0.59(0.44-0.78)$ & $<0.001$ & $0.48(0.36-0.64)$ & $<0.001$ \\
\hline \multicolumn{5}{|l|}{ Overweight/obese } \\
\hline No & Reference & & Reference & \\
\hline Yes & $1.29(1.10-1.52)$ & 0.002 & $1.18(1.00-1.38)$ & 0.042 \\
\hline
\end{tabular}

45, 56]. As expected, participants with higher education level and with formal employment were more knowledgeable about risk factors and warning signs compared to their counterparts. Other studies have also reported a positive association between higher education level with good CVD knowledge [12, 42, 54, 56, 57]. Educated individuals have higher capabilities to comprehend information including health messages delivered through various mass media channels.

Studies have reported geographical differences in CVD knowledge with those in urban settings having better knowledge compared to their counterparts in rural settings $[16,56]$. Despite the fact that both Kilombero and Ulanga are rural districts, residents of Ulanga district 
Table 7 Perception and practices towards CVD prevention

\begin{tabular}{ll}
\hline & Number (\%) \\
\hline Self-perceived risk & $1360(45.3)$ \\
Perceive to be at risk of cardiovascular disease & $921(30.7)$ \\
Perceive to be overweight/obese & $956(31.9)$ \\
Perceive body weight has increased in the past 1 year & 826 (27.5) \\
Practices towards CVD prevention in the past 1 year & 495 (16.5) \\
Conducted medical check-up for CVD risk factors & $1412(47.1)$ \\
Decreased amount of food eaten so as loose or not gain weight & $1482(49.4)$ \\
Decreased amount of salt in food & 1205 (40.2) \\
Reduced consumption of fatty foods & 412 (13.7) \\
Decreased eating fast foods and out of home & $10(5.7)$ \\
Exercise regularly & $128(21.7)$ \\
Attempted to stop /decreased smoking (among smokers) & \\
Attempted to stop / decreased alcohol drinking (among drinkers) &
\end{tabular}

had significantly higher knowledge about risk factors and warning signs than their counterparts from Kilombero district. Although this study did not assess ownership of community health fund (CHF) cards to draw its association with CVD knowledge, higher coverage of CHF overcomes the financial barrier to accessing health care services and consequently increase their likelihood of getting health-related messages and increase knowledge. Nonetheless, differences in CVD knowledge between the two rural districts warranties further exploration.

Behavior change is mostly influenced by one's perception and knowledge that such behavior may cause harm to their health [58]. More than half (59.1\%) of the participants had moderate to good knowledge of risk factors and warning signs for CVD. Consistent with knowledge, a reasonably good number $(45.3 \%)$ of the participants perceived themselves to be at risk for CVD. Nearly onethird perceived themselves to be overweight or obese and that they had gained weight in the past 1 year. As for practices, only $5.7 \%$ of smokers had attempted to stop or decreased smoking while $21.7 \%$ had decreased drinking alcohol in the past 1 year. These findings indicate that interventions to increase population knowledge are needed to improved people's perceptions and behavior change towards healthy lifestyle in order to combat the rising burden of CVDs in Tanzania.

\section{Conclusion}

Knowledge of risk factors and warning signs in this rural population of young and middle-aged Tanzanian adults was generally still low. In order to combat the increasing burden of CVD risk factors in Tanzania, it is critical to develop and implement interventions that will improve population knowledge of risk factors. In this study, health care providers were not identified as key sources of information and knowledge about CVDs to the community, indicating that their primary focus is centered on treatment and that provision of preventive health messages is not emphasized. There is a need for paradigm shift to maximize the potential of health care providers as channels of health information to increase public knowledge of risk factors and warning signs especially in rural areas. As it is the case of health talk to pregnant women at the Reproductive and Child Health (RCH) clinics, such strategy can be translated so that outpatient clinics provide health talk on CVDs, risk factors and warning signs. With increased access to electricity through Rural Energy Agency (REA), cardiovascular-related health messages can be provided through Video Compact Discs (VCDs) played at outpatient clinics and visitors waiting areas. Additionally, community-based interventions through outreach programs by health care providers and CHWs as well as mass media campaigns should be implemented to improve public knowledge about CVDs and their risk factors. This way, rural communities will be empowered with knowledge to make informed choices regarding healthy lifestyles.

\section{Supplementary Information}

The online version contains supplementary material available at https://doi. org/10.1186/s12889-020-09956-z.

\section{Additional file 1.}

\section{Abbreviations}

BMI: Body mass index; CHF: Community health fund; CHWs: Community health workers; CVDs: Cardiovascular diseases; DALYs: Disability adjusted lifeyears; HDSS: Health and demographic surveillance system; LMICs: Low and middle-income countries; RCH: Reproductive and child health; REA: Rural 
energy agency; SSA: Sub-Saharan Africa; VCDs: Video compact discs; WHO: World health organization

\section{Acknowledgements}

The authors are grateful to research assistants, Kilombero and Ulanga district authorities and all study participants for their time and contribution to these findings.

\section{Authors' contributions}

AJM, MN and DPU conceptualized the study. AJM and AA led the data collection process. AJM wrote the analysis plan and conducted data analysis with support from RNM, MN. AJM conducted literature review and wrote the first draft of the manuscript with support from AA under the supervision of MN and DPU. RNM, BFS, GL, DK, ATK, MMS, MN and DPU critically reviewed, and provided intellectual input to the manuscript. RNM and MN suggested additional analyses. AJM made the proposed revisions and finalized the manuscript. All authors read and approved the final version of the manuscript.

\section{Funding}

This study was possible with financial support from the Bernard Lown Scholars in Cardiovascular Health Program at Harvard T.H Chan School of Public Health (Agreement \#BLSCHP-1901) to Dr. Alfa Muhihi and the SIDA small grant award from Muhimbili University of Health and Allied Sciences to Dr. Amani Anaeli. The funding agencies were not involved in the study design, neither in data collection, analysis and interpretation of the findings, preparation of the manuscript nor decision to publish. The findings and their interpretations solely present views of the authors and do not necessarily reflect views of the funders.

\section{Availability of data and materials}

Datasets analysed for the current study are available from the corresponding author at reasonable request.

\section{Ethics approval and consent to participate}

The study was approved by research ethics review committee of Muhimbili University of Health and Allied Sciences (MUHAS-REC-1-2017-070). All study participants received information about study objectives, procedures, importance, risks and benefits and voluntary participation. A written informed consent was obtained from all participants before joining the study.

\section{Consent for publication}

Not applicable.

\section{Competing interests}

The authors declare that they have no competing interests.

\section{Author details}

'Department of Community Health, Muhimbili University of Health and Allied Sciences, United Nations Road, P. O. Box 65001, Upanga, Dar es Salaam, Tanzania. ${ }^{2}$ Africa Academy for Public Health, Plot \# 802, Mwai Kibaki Road, Mikocheni, Dar es Salaam, Tanzania. 'Lown Scholars Program, Department of Global Health and Population, Harvard T.H. Chan School of Public Health, Boston, MA, USA. ${ }^{4}$ Department of Development Studies, Muhimbili University of Health and Allied Sciences, United Nations Road, Upanga, Dar es Salaam, Tanzania. ${ }^{5}$ Department of Epidemiology and Biostatistics, Muhimbili University of Health and Allied Sciences, United Nations Road, Upanga, Dar es Salaam, Tanzania. ${ }^{6}$ Department of Behavioral Sciences, Muhimbili University of Health and Allied Sciences, United Nations Road, Upanga, Dar es Salaam, Tanzania. ${ }^{7}$ Department of Physiology, Muhimbili University of Health and Allied Sciences, United Nations Road, Upanga, Dar es Salaam, Tanzania. ${ }^{8}$ Deloitte Consulting Limited, Aris House, Plot \# 152, Haile Selassie Road, Oysterbay, Dar es Salaam, Tanzania.

Received: 19 June 2020 Accepted: 22 November 2020 Published online: 30 November 2020

\section{References}

1. Hay SI, Abajobir AA, Abate KH, Abbafati C, Abbas KM, Abd-Allah F, et al. Global, regional, and national disability-adjusted life-years (DALYs) for 333 diseases and injuries and healthy life expectancy (HALE) for 195 countries and territories, 1990-2016: a systematic analysis for the global burden of disease study 2016. Lancet. 2017;390:1260-344.

2. Roth GA, Abate D, Abate KH, Abay SM, Abbafati C, Abbasi N, et al. Global, regional, and national age-sex-specific mortality for 282 causes of death in 195 countries and territories, 1980-2017: a systematic analysis for the global burden of disease study 2017. Lancet. 2018;392:1736-88.

3. World Health Organization. Global Status Report On Noncommunicable Diseases 2014. Geneva: WHO; 2014.

4. Keates AK, Mocumbi AO, Ntsekhe M, Sliwa K, Stewart S. Cardiovascular disease in Africa: epidemiological profile and challenges. Nat Rev Cardiol. 2017;14:273-93.

5. Yusuf S, Reddy S, Ounpuu S, Anand S. Global burden of cardiovascular diseases: part II: variations in cardiovascular disease by specific ethnic groups and geographic regions and prevention strategies. Circulation. 2001; 104:2855-64.

6. Laatikainen T, Critchley J, Vartiainen E, Salomaa V, Ketonen M, Capewell S. Explaining the decline in coronary heart disease mortality in Finland between 1982 and 1997. Am J Epidemiol. 2005:162:764-73.

7. Koopman C, Vaartjes I, van Dis I, Verschuren WMM, Engelfriet P, Heintjes EM, et al. Explaining the decline in coronary heart disease mortality in the Netherlands between 1997 and 2007. PLoS One. 2016;11:e0166139.

8. Wijeysundera HC, Machado M, Farahati F, Wang X, Witteman W, Van Der Velde $\mathrm{G}$, et al. Association of temporal trends in risk factors and treatment uptake with coronary heart disease mortality, 1994-2005. JAMA. 2010;303: 1841-7.

9. Perk J, De Backer G, Gohlke H, Graham I, Reiner Ž, Verschuren WMM, et al. European guidelines on cardiovascular disease prevention in clinical practice (version 2012): the fifth joint task force of the European society of cardiology and other societies on cardiovascular disease prevention in clinical practice. Int J Behav Med. 2012;19:403-88.

10. Rosenstock IM, Strecher VJ, Becker MH. Social learning theory and the health belief model. Health Educ Behav. 1988;15:175-83.

11. Mendis S, Puska P, Norrving B. Global atlas on cardiovascular disease prevention and control. Geneva: World Heal Organ; 2011. p. 2-14.

12. Aminde LN, Takah N, Ngwasiri C, Noubiap JJ, Tindong M, Dzudie A, et al. Population awareness of cardiovascular disease and its risk factors in Buea, Cameroon. BMC Public Health. 2017;17:545.

13. Oladapo O. Knowledge of hypertension and other risk factors for heart disease among Yoruba rural southwestern Nigerian population. $\mathrm{Br}$ J Med Med Res. 2013;3:993-1003.

14. Donkor ES, Owolabi MO, Bampoh P, Aspelund T, Gudnason V. Community awareness of stroke in Accra, Ghana. BMC Public Health. 2014;14. https://doi. org/10.1186/1471-2458-14-196.

15. Kaddumukasa M, Kayima J, Kaddumukasa MN, Ddumba E, Mugenyi L, Pundik S, et al. Knowledge, attitudes and perceptions of stroke: a crosssectional survey in rural and urban Uganda. BMC Res Notes. 2015;8:819.

16. Nakibuuka J, Sajatovic M, Katabira E, Ddumba E, Byakika-Tusiime J, Furlan AJ. Knowledge and perception of stroke: a population-based survey in Uganda. ISRN Stroke. 2014;2014:1-7.

17. Surka S, Steyn K, Everett-Murphy K, Gaziano TA, Levitt N. Knowledge and perceptions of risk for cardiovascular disease: findings of a qualitative investigation from a low-income peri-urban community in the Western cape, South Africa. African J Prim Health Care Fam Med. 2015;7. https://doi. org/10.4102/phcfm.v7i1.891.

18. Uchenna D, Ambakederemo T, Jesuorobo D. Awareness of heart disease prevention among patients attending a specialist Clinic in Southern Nigeria. Int J Prev Treat. 2012;1:40-3.

19. Jingi AM, Noubiap JJN. Cardiovascular risk factors awareness and prevalence among primary care physicians: an insight from the west region awareness initiative survey to fight cardiovascular disease (WAIT-CVD) in Cameroon public health. BMC Res Notes. 2015;8:762.

20. Joshi MD, Ayah R, Njau EK, Wanjiru R, Kayima JK, Njeru EK, et al. Prevalence of hypertension and associated cardiovascular risk factors in an urban slum in Nairobi, Kenya: a population-based survey. BMC Public Health. 2014;14. https://doi.org/10.1186/1471-2458-14-1177.

21. Akintunde A, Akintunde T, Opadijo O. Knowledge of heart disease risk factors among workers in a Nigerian University: A call for concern. Niger Med J. 2015:56:91 
22. Temu TM, Kirui N, Wanjalla C, Ndungu AM, Kamano JH, Inui TS, et al Cardiovascular health knowledge and preventive practices in people living with HIV in Kenya. BMC Infect Dis. 2015;15:421.

23. Komolafe MA, Obembe AO, Olaogun MO, Adebiyi AM, Ugalahi T, Dada O, et al. Awareness of stroke risk factors and warning signs in nigerian adolescents compared with adults. J Stroke Cerebrovasc Dis. 2015;24:68793.

24. Mohammed J. Knowledge of, and attitude to cardiovascular disease risk factors among members of the Nigerian armed forces. World J Public Health Sci Cardiovasc Dis Risk Factors Niger Armed Forces Serv World J Public Health Sci. 2012;11:23-7.

25. Boateng D, Wekesah F, Browne JL, Agyemang C, Agyei-Baffour P, De-Graft Aikins $A$, et al. Knowledge and awareness of and perception towards cardiovascular disease risk in sub-Saharan Africa: a systematic review. PLoS One. 2017;12. https://doi.org/10.1371/journal.pone.0189264.

26. Jafary FH, Aslam F, Mahmud H, Waheed A, Shakir M, Afzal A, et al. Cardiovascular health knowledge and behavior in patient attendants at four tertiary care hospitals in Pakistan - a cause for concern. BMC Public Health. 2005;5. https://doi.org/10.1186/1471-2458-5-124.

27. Hamid S, Groot W, Pavlova M. Trends in cardiovascular diseases and associated risks in sub-Saharan Africa: a review of the evidence for Ghana, Nigeria, South Africa, Sudan and Tanzania. Aging Male. 2019;22:169-76.

28. Roman WP, Martin HD, Sauli E. Cardiovascular diseases in Tanzania: the burden of modifiable and intermediate risk factors. J Xiangya Med. 2019;4: 33.

29. Muhihi AJ, Urassa DP, Mpembeni RNM, Leyna GH, Sunguya BF, Kakoko D, et al. Effect of training community health workers and their interventions on cardiovascular disease risk factors among adults in Morogoro, Tanzania: Study protocol for a cluster randomized controlled trial. Trials. 2018;19:552.

30. NBS. The 2012 Tanzania population and housing census: basic demographic and socio-economic profile for Dar Es Salaam region. Dar es Salaam: National Bureau of Statistics; 2016.

31. Beguy D, Elung'ata P, Mberu B, Oduor C, Wamukoya M, Nganyi B, et al. Health \& demographic surveillance system profile: the Nairobi urban health and demographic surveillance system (NUHDSS). Int J Epidemiol. 2015;44: $462-71$.

32. WHO. NCDs|WHO STEPS Sample Size Calculator and Sampling Spreadsheet: WHO; 2015. https://www.who.int/ncds/surveillance/steps/resources/ sampling/en/.

33. Kagaruki G, Mary M. Tanzania Steps Survey Report: Ministry of Health and Social Welfare and National Institute for Medical Research. Dar es Salaam: ResearchGate; 2016.

34. NBS. Tanzania Demographic and Health Survey and Malaria Indicator Survey. Dar es Salaam: Ministry of Health, Community Development, Gender, Elderly and Children (MoHCGEC); 2016.

35. Vyas S, Kumaranayake L. Constructing socio-economic status indices: how to use principal components analysis. Health Policy Plan. 2006;21:459-68.

36. Robinson JP, Shaver PR, Wrightsman LS. Criteria for scale selection and evaluation. In: Measures of Personality and Social Psychological Attitudes; 1991.

37. Chobanian AV, Bakris GL, Black HR, Cushman WC, Green LA, Izzo JL, et al. The seventh report of the joint National Committee on prevention, detection, evaluation, and treatment of high blood pressure: the JNC 7 report. JAMA. 2003;289:2560-72.

38. Osama A, Ashour Y, El-Razek RA, Mostafa I. Public knowledge of warning signs and risk factors of cerebro-vascular stroke in Ismailia governorate, Egypt. Egypt J Neurol Psychiatry Neurosurg. 2019;55:31.

39. Cossi MJ, Preux PM, Chabriat H, Gobron C, Houinato D. Knowledge of stroke among an urban population in Cotonou (Benin). Neuroepidemiology. 2012; 38:172-8.

40. Awosan KJ, Ibrahim MTO, Sabir AA. Awareness and prevalence of risk factors of coronary heart disease among teachers and bankers in Sokoto, Nigeria. J Med Med Sci. 2013;4:335-42.

41. Ajayi AO, Ojo OO. Knowledge and perception of stroke among at risk medical out-patients in a tertiary health institution in Nigeria. Ann Afr Med. 2007;6:51-3.

42. Awad A, Al-Nafisi H. Public knowledge of cardiovascular disease and its risk factors in Kuwait: a cross-sectional survey. BMC Public Health. 2014;14. https://doi.org/10.1186/1471-2458-14-1131.
43. Akinyemi RO, Owolabi MO, Adebayo PB, Akinyemi JO, Otubogun FM, Uvere E, et al. Task-shifting training improves stroke knowledge among Nigerian non-neurologist health workers. J Neurol Sci. 2015;359:112-6.

44. Akinyemi RO, Ogah OS, Ogundipe RF, Oyesola OA, Oyadoke AA, Ogunlana $\mathrm{MO}$, et al. Knowledge and perception of stroke amongst hospital workers in an African community. Eur J Neurol. 2009;16:998-1003.

45. Obembe AO, Olaogun MO, Bamikole AA, Komolafe MA, Odetunde MO. Awareness of risk factors and warning signs of stroke in a Nigeria University. J Stroke Cerebrovasc Dis. 2014;23:749-58.

46. Yuqiu L, Dreyer Wright SC. Knowledge and awareness of risk factors for cardiovascular disease in the Ga-Rankuwa community. Health SA Gesondheid. 2008;13:31-41.

47. Pan $B$, Jin $X$, Jun $L$, Qiu S, Zheng Q, Pan M. The relationship between smoking and stroke: A meta-analysis. Medicine (Baltimore). 2019;98:e14872.

48. Malek AM, Cushman M, Lackland DT, Howard G, McClure LA. Secondhand smoke exposure and stroke: the reasons for geographic and racial differences in stroke (REGARDS) study. Am J Prev Med. 2015;49:e89-97.

49. MoHCDGEC. Tanzania STEPwise Survey of Non-Communicable Disease Risk Factors. Dar es Salaam: National Institute for Medical Research; 2012.

50. McKinley S, Dracup K, Moser DK, Ball C, Yamasaki K, Kim CJ, et al. International comparison of factors associated with delay in presentation for AMI treatment. Eur J Cardiovasc Nurs. 2004;3:225-30.

51. Becker MH, Maiman LA, Kirscht JP, Haefner DP, Drachman RH. The health belief model and prediction of dietary compliance: a field experiment. J Health Soc Behav. 1977;18:348-66.

52. Attarchi M, Mohammadi S, Nojomi M, Labbafinejad Y. Knowledge and practice assessment of workers in a pharmaceutical company about prevention of coronary artery disease. Acta Med Iran. 2012;50:697-703.

53. Abate AT, Bayu N, Mariam TG. Hypertensive patients' knowledge of risk factors and warning signs of stroke at Felege Hiwot referral hospital, Northwest Ethiopia: a cross-sectional study. Neurol Res Int. 2019;2019. https://doi.org/10.1155/2019/8570428.

54. Mukattash TL, Shara M, Jarab AS, Al-Azzam SI, Almaaytah A, Al Hamarneh YN. Public knowledge and awareness of cardiovascular disease and its risk factors: a cross-sectional study of 1000 Jordanians. Int J Pharm Pract. 2012; 20:367-76.

55. Vaidya A, Aryal UR, Krettek A. Cardiovascular health knowledge, attitude and practice/behaviour in an urbanising community of Nepal: a populationbased cross-sectional study from Jhaukhel-Duwakot health demographic surveillance site. BMJ Open. 2013;3. https://doi.org/10.1136/bmjopen-2013002976.

56. Wahab KW, Kayode OO, Musa Ol. Knowledge of stroke risk factors among Nigerians at high risk. J Stroke Cerebrovasc Dis. 2015;24:125-9.

57. Al Hamarneh YN, Crealey GE, McElnay JC. Coronary heart disease: health knowledge and behaviour. Int J Clin Pharm. 2011;33:111-23.

58. Choi S, Rankin S, Stewart A, Oka R. Perceptions of coronary heart disease risk in Korean immigrants with type 2 diabetes. Diabetes Educ. 2008;34:48492.

\section{Publisher's Note}

Springer Nature remains neutral with regard to jurisdictional claims in published maps and institutional affiliations.

Ready to submit your research? Choose BMC and benefit from:

- fast, convenient online submission

- thorough peer review by experienced researchers in your field

- rapid publication on acceptance

- support for research data, including large and complex data types

- gold Open Access which fosters wider collaboration and increased citations

- maximum visibility for your research: over $100 \mathrm{M}$ website views per year

At BMC, research is always in progress.

Learn more biomedcentral.com/submission 